\title{
As três Marias, de Rachel de Queiroz: literatura e subjetividade
}

\author{
Alex Sander Luiz Campos \\ Mestrando em Estudos Literários / UFMG. Bolsista do programa Capes/Reuni
}

\begin{abstract}
RESUMO
Este trabalho ${ }^{1}$ contempla a composição da narradora Maria Augusta, a Guta do romance As três Marias, de Rachel de Queiroz. Para discutir a construção de sua subjetividade, partiu-se das referências literárias presentes no livro, possibilitando analisar a protagonista como leitora, bem como sua visão romanceada da realidade.
\end{abstract}

\section{PALAVRAS-CHAVE}

As três Marias, Rachel de Queiroz, subjetividade, referências literárias

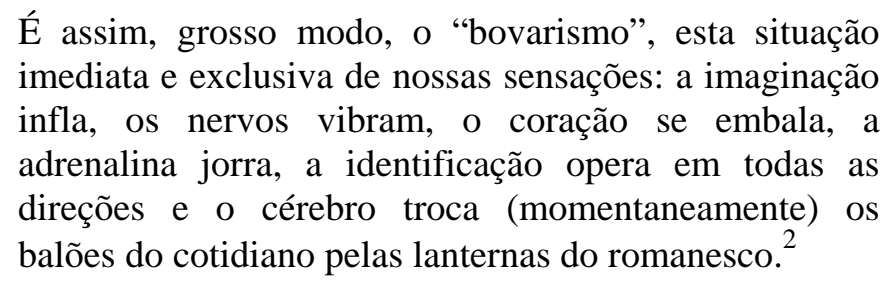

A epígrafe colhida de Como um romance, de Daniel Pennac, traz uma imagem significativa para pensar a personagem Maria Augusta, a Guta do romance As três Marias, de Rachel de Queiroz: a troca dos balões do cotidiano pelas lanternas do romanesco. Durante toda a narrativa, somos leitores atentos às peripécias de uma protagonista que é, possivelmente, uma leitora por excelência. É a própria Maria Augusta quem diz: "Falei em livro. É que vivíamos lendo, então.”’ E o que não falta em As três Marias são referências ao mundo da literatura, passando pelo “centro do cânone” Shakespeare à literatura de massa, de aventuras, “cor-de-rosa”. Também há referências a gêneros literários, personagens, versos,

\footnotetext{
${ }^{1}$ Versão deste texto foi apresentada como comunicação ao III Colóquio e I Encontro Nacional Mulheres em Letras - "Escritoras de ontem e de hoje", evento realizado na Faculdade de Letras da UFMG entre os dias 5 e 7 de maio de 2011

2 PENNAC. Como um romance, p. 157.

${ }^{3}$ QUEIROZ. As três Marias, p. 33.
} 
enfim, uma série de alusões que reclama uma investigação de sua natureza e importância quanto à composição dos personagens de As três Marias. Em linhas gerais, é a isso que se propõe o presente trabalho, privilegiando a construção da subjetividade da personagem Guta uma vez que é por intermédio de seu olhar que conhecemos os demais personagens.

A estreia de Rachel de Queiroz na literatura se dá em fins de 1930, quando publica o romance $O$ quinze - e é com entusiasmo que a crítica recebe a obra. Depois aparecem João Miguel, Caminho de pedras e, em 1939, numa temática bem diferente de seu primeiro romance, As três Marias, romance dessa vez centrado em um conflito subjetivo, familiar. Novamente, a recepção da literatura de Rachel de Queiroz é muito positiva, como demonstra o parecer de Mário de Andrade, citado por Hermes Nery: “Ninguém distribui certidão de obra-prima. Em todo caso, As três Marias [...] me parece uma das obras mais belas e ao mesmo tempo mais intensamente vividas da nossa literatura contemporânea.”4

Positivo também é o parecer do historiador da literatura Afrânio Coutinho, que vê em As três Marias, ao contrário de certa crítica que concede tal lugar a O quinze, "sua [de Rachel de Queiroz] obra-prima, e um dos romances mais significativos do Modernismo". 5 Argumenta ainda o diretor de A literatura no Brasil que, "abandonando um pouco a linearidade, aperfeiçoando a técnica, recorrendo à introspecção através do relato feito por uma das personagens, Maria Augusta, o senso trágico da vida, característico da autora, assume altas proporções."6

O estudo da construção da subjetividade da personagem de Rachel de Queiroz se justifica pela importância que a escritora cearense concede, no ato da criação ficcional, à composição dos personagens. Em entrevista a Hermes Nery, publicada no livro Presença de Rachel, a primeira imortal da Academia Brasileira de Letras relata que,

para criar a cena, você primeiro a visualiza. É muito parecido com o cinema. As personagens acabam se impondo no seu roteiro, vão assumindo aos poucos a sua forma e a sua intensidade. A personagem tem fome, mata a cabra, a cabra tem dono, o dono aparece, a personagem fica acabrunhada por ter que passar aquela humilhação toda, tem as suas reações, e assim por diante. De repente, a história vai fluindo. (...) As situações vão surgindo, as personagens aparecendo e o enredo vai se construindo. ${ }^{7}$

\footnotetext{
${ }^{4}$ NERY. Presença de Rachel: conversas informais com a escritora Rachel de Queiroz, p. 336.

${ }^{5}$ COUTINHO. A literatura no Brasil, p. 280. É notável que a produção ficcional da autora de $O$ quinze ainda não estava concluída quando da publicação de A literatura no Brasil.

${ }^{6}$ COUTINHO. A literatura no Brasil, p. 280.

${ }^{7}$ NERY. Presença de Rachel: conversas informais com a escritora Rachel de Queiroz, p. 69.
} 
Dessa forma, a criação de Rachel de Queiroz privilegia o personagem perante um roteiro preconcebido, em consonância com Muniz Sodré, quando este afirma que “o personagem é o lugar tenente da subjetividade na narrativa romanesca”, e é difícil, senão impossível imaginar o romance sem personagem. ${ }^{8}$ No caso da Maria Augusta de As três Marias, há pelo menos mais uma peculiaridade: o caráter autobiográfico da personagem. É Rachel de Queiroz quem afirma: “A Guta sou eu.”9 Além disso, uma característica em comum, relevante para este trabalho, une a autora a sua protagonista: a leitura por prazer, a abertura à leitura de diversas espécies de literatura. Na mesma entrevista citada, Rachel de Queiroz admite que

ainda hoje não leio livro chato. O que acho chato, eu paro. Pode ser a obra mais importante do mundo, se não der prazer, não fico tentando terminar de ler, só para dizer: "Olha, eu li." O livro tem que me prender. Leio sobre todas as coisas. Adoro Dostoievski, mas gosto de outros tipos de literatura. Sou aberta a quase toda espécie de leitura. Não sei, é aquilo que já disse: quando é chato, eu largo. ${ }^{10}$

A seguir, propomos uma leitura da construção da subjetividade de Guta a partir de suas escolhas literárias e demais referências presentes em As três Marias. Faremos uso tanto de estudiosos da obra de Rachel de Queiroz quando de autores que discutem o ato de ler, de modo a compreender no que as leituras de Guta podem nos auxiliar no entendimento de sua visão e de sua relação com outros personagens: de uma leitura que reforça preconceitos e uma visão alienante da realidade a uma leitura dos clássicos, da grande poesia.

\section{SUBJETIVIDADE E REFERÊNCIAS LITERÁRIAS EM AS TRÊS MARIAS}

Joana Alves Fhiladelfio, no artigo "Literatura, indústria cultural e formação humana”, discute as potencialidades de discursos diferentes na formação da subjetividade do leitor, utilizando como referência duas protagonistas de Rachel de Queiroz: Conceição, de $O$ quinze, e Maria Augusta, de As três Marias. ${ }^{11}$ Conforme a autora, as duas personagens citadas possibilitam conhecer os efeitos da leitura na construção da identidade - o que ocorreu de maneira distinta e oposta em relação a Conceição e Guta, pois, enquanto Conceição é a mais intelectual das heroínas de Rachel de Queiroz, demonstração de que a literatura a tornou

\footnotetext{
${ }^{8}$ SODRÉ. Teoria da literatura de massa, p. 53.

${ }^{9}$ NERY. Presença de Rachel: conversas informais com a escritora Rachel de Queiroz, p. 108.

${ }^{10}$ NERY. Presença de Rachel: conversas informais com a escritora Rachel de Queiroz,, p. 72.

${ }^{11}$ FHILADELFIO. Literatura, indústria cultural e formação humana.
} 
crítica perante a realidade, interferindo nas suas atitudes, a Guta de As três Marias, em virtude das leituras que fez, impregnou-se de uma imagem romântica, deturpada, preconceituosa da realidade. $^{12}$

De fato, não parece ser outra a imagem que Guta tem de uma de suas amigas do Colégio, Glória, outra das três Marias: uma imagem romanesca. Glória nos é apresentada como uma órfã singular, aparentemente uma construção literária da própria narradora: “entre tantas outras que não tinham pai ou não tinham mãe, a orfandade de Glória revestia-se de não sei que características sutis que a tornavam excepcional - como de uma aristocracia na tragédia."13 A própria alusão à tragédia, e de uma "aristocracia na tragédia”, demonstra como as leituras feitas por Guta podem ter influenciado em sua visão da realidade. Mais à frente na narrativa, vamos conhecer a história de Glória - novamente, as referências literárias se fazem presente: a mãe de Glória morrera ao dar à luz; o pai então substitui a morta, era pai e mãe. “O pai fazia versos. Glória tinha um cofre (...) cheio de sonetos e baladas (...) Versos à morta, versos de saudades e mágoa revoltada. E outra espécie de versos também, esses alegres ou comovidos, acompanhando musicalmente a infância da filha.” ${ }^{\text {"4 }}$ Quando o pai de Glória morre, Guta ressalva que "acabaram-se os versos”. ${ }^{15}$ Só por aí notamos, para a narrativa de Guta, a importância da literatura como uma espécie de metáfora da vida.

Muitas vezes a imagem idealizada de algum personagem era desenvolvida também pelas narrações orais a que Guta teve acesso, mas sem excluir as interpretações romanescas. Dessa forma, importa conhecer como Maria da Glória é retratada:

Entrou no Colégio toda vestida de preto, o cabelo escorrido batendo nos ombros, o grande medalhão brilhando ao peito, no meio da negrura do luto, a caixa do violino debaixo do braço. Porque ela tinha até um violino para completar o quadro, era realmente a órfã, pálida, magrinha, (...), como se tivesse saído de uma gravura daqueles romances que nós líamos em voz alta nos recreios da noite - romances cujos começos são tão tristes, mas que acabam sempre pelo casamento da orfãzinha com o moço orgulhoso, de olhos azuis de aço, motejadores e escaninhos, filho do dono do castelo onde ela é professora. ${ }^{16}$

O trecho reproduzido mostra como Glória era romantizada pela protagonista Guta, embora ela fizesse também distinções entre a amiga e as órfãs da literatura: “[Glória] não era

\footnotetext{
${ }^{12}$ FHILADELFIO. Literatura, indústria cultural e formação humana.

${ }^{13}$ QUEIROZ. As três Marias, p. 12.

${ }^{14}$ QUEIROZ. As três Marias, p. 19-20.

${ }^{15}$ QUEIROZ. As três Marias, p. 20.

${ }^{16}$ QUEIROZ. As três Marias, p. 21.
} 
humilde nem meiga como as outras órfãs, as dos romances.”17 Também Jandira, colega que tinha afinidades com as “três Marias” - as já citadas Maria Augusta, Maria da Glória e Maria José -, é apresentada com recurso à literatura: “Era risonha, apaixonada, inteligente, sabia recitar em francês e já brilhara numa festa de fim de ano, declamando La mort de Jeanne d’Arc, vestida de arlesiana.”18 Além da poesia francesa, há referência à poesia antológica brasileira, na figura de um Raimundo Correia - seus poemas (“As pombas”, "Três irmãs”, “Mal secreto”) eram parafraseados de forma burlesca pelas três Marias e Jandira, autoras do jornal satírico Santa Gaiola, impresso à mão, em que as adolescentes faziam uso da literatura destrutiva, em forma de versos. ${ }^{19}$ Quando elas descobrem que uma colega está apaixonada pelo professor de História, passam a chamá-los de “Dom Pedro” e “donzela Dona Inês”, numa clara referência ao canto III de Os Lusíadas. ${ }^{20}$ Por essa referência se nota que não é somente a literatura de massa que é lida por Guta, ou a que ela tem contato.

Por outro lado, não se pode negar a preferência de Maria Augusta pelos versos franceses e romances “cor-de-rosa”. Quanto ao primeiro fato, basta ver as referências aos poetas Paul Géraldy, André Spire e François Villon, conhecidos pela sentimentalidade e pela estima que lhes têm as mulheres. Quanto ao segundo fato, é significativo quando Guta, em um capítulo que trata da descoberta da literatura, afirma que “qualquer de nós trocaria todo o Shakespeare (inclusive Romeu e Julieta) por um só volume da Passageira ou de Mon oncle et mon curé." ${ }^{21}$ Ressaltemos que Romeu e Julieta parece ser uma obra apreciada pelas colegiais, uma vez que, quando Teresa e o namorado fogem, eles são comparados aos amantes de Verona. ${ }^{22}$ Mesmo assim, o que seria Shakespeare para as colegiais diante de Jean de la Brète (pseudônimo de Alice Cherbonnel) ou Guy Chantepleure (pseudônimo de Jeanne-Caroline Violet)? A preferência por esse tipo de literatura representa, segundo Fhiladelfio, um mundo de aspirações ilusórias para as Marias, uma “conselheira que dá dicas para solução de problemas pessoais”. ${ }^{23}$ É por meio dessa literatura que Guta e as colegas procuram ter algum contato com o mundo exterior que elas não têm. Mas, evidentemente, de forma idealizada, romanceada.

\footnotetext{
${ }^{17}$ QUEIROZ. As três Marias, p. 22

${ }^{18}$ QUEIROZ. As três Marias, p. 22.

${ }^{19}$ Cf. QUEIROZ. As três Marias, p. 22-23.

${ }^{20}$ Cf. QUEIROZ. As três Marias, p. 23.

${ }^{21}$ QUEIROZ. As três Marias, p. 34.

${ }^{22}$ Cf. QUEIROZ. As três Marias, p. 66.

${ }^{23}$ FHILADELFIO. Literatura, indústria cultural e formação humana, p. 212.
} 
Evidentemente, nem toda a literatura apresenta uma imagem "romântica” da guerra. Exemplo disso é o Nada de novo no front (1929), do escritor alemão Erich Maria Remarque, que não é bem aceito por Guta e suas amigas:

A guerra, só a compreendíamos com heróis esbeltos, vestidos de azulhorizonte, voltando, levemente mutilados e cobertos de medalhas, para os braços da amada. Aquela guerra suja e sem poesia, as latrinas, as pragas, o medo e a miséria dos soldados apenas nos trouxeram indignação, nojo. ${ }^{24}$

Em estudo sobre a escritura feminina, Cristina Pinto percebe uma similaridade entre o romance de Erich Remarque e a própria história de Guta. Em contato com a realidade da guerra, o idealismo dos jovens que se alistaram desaparece rapidamente. Assim também Guta, quando sai do internato repleta de sonhos, de ideais - eles são triturados pela realidade exterior e obrigam a protagonista a voltar à casa do pai. ${ }^{25}$

A escolha dos livros por parte das adolescentes também exemplifica o que diz Richard Bamberger: “O jovem leitor lê não porque reconheça a importância da leitura, mas por várias mediações e interesses que correspondem à sua personalidade e ao seu desenvolvimento intelectual." ${ }^{26}$ É preciso levar em consideração a "fase de leitura” em que se encontravam Guta e suas colegas, o que indica, para Bamberger, o nível de desenvolvimento intelectual do indivíduo. ${ }^{27}$ Partindo da proposta desse pesquisador, Guta estaria vivendo, no período do Colégio, a "idade da história de aventuras", do "realismo aventuroso" ou a "fase de leitura apsicológica, orientada para as sensações”. A descrição dessa fase feita por Bamberger permite-nos compreender algumas atitudes de Maria Augusta:

Durante os processos de desenvolvimento pré-adolescentes, a criança, pouco a pouco, toma consciência da própria personalidade, afrouxa ou desfaz elos anteriores (a segunda idade de desconfiança e desafio). Esta é a idade em que predominam as demonstrações de agressividade e a formação de gangues. $\mathrm{O}$ interesse dos leitores pode despertar, principalmente através do enredo, dos acontecimentos, do sensacionalismo. Em se tratando de meninas, (...) surge amiúde em primeiro plano, bem como o interesse pelo sentimentalismo barato e pela auto-adulação. Interesses gerais: livros de aventuras, romances sensacionais, livros de aventuras, romances sensacionais, livros de viagens, histórias ordinárias e de um sentimentalismo barato. $^{28}$

\footnotetext{
${ }^{24}$ QUEIROZ. As três Marias, p. 34.

${ }^{25}$ PINTO. O Bildungsroman feminino: quatro exemplos brasileiros.

${ }^{26}$ BAMBERGER. Como incentivar o hábito da leitura, p. 34.

${ }^{27}$ BAMBERGER. Como incentivar o hábito da leitura, p. 36.

${ }^{28}$ BAMBERGER. Como incentivar o hábito da leitura, p. 38.
} 
Com efeito, Guta e as outras duas Marias viviam sempre juntas, possivelmente como a “gangue” a que se refere Bamberger; é o que sugere tanto a fala de Irmã Germana: “- Maria José, Maria Augusta, Maria da Glória, por que não fazem silêncio? São as inseparáveis! (...) Essas três vivem juntas, conversando, vadiando, afastadas de todas”, ${ }^{29}$ quanto a algumas de suas atitudes no Colégio, como a criação do jornal satírico. Além disso, as leituras preferidas pelas adolescentes encaixam-se na proposta de Bamberger para essa fase de leitura, como demonstram a alusão, em As três Marias, a Robinson Crusoé, Pedro Malasarte, D’Artagnan, a Esmeralda de Notre-Dame de Paris, Gulliver, Capitão Nemo, dentre outros.

Ao contrário do estudo já citado, de Fhiladelfio, em que a Conceição d’O quinze e Maria Augusta são estudadas como opostas entre si no que se refere às dimensões da leitura, o estudo de Wanessa da Silva busca uma aproximação entre essas protagonistas de Rachel de Queiroz, ressaltando que ambas representam perfis femininos distintos dos modelos até então representados na literatura brasileira. Para Silva, as duas personagens antecipam comportamentos que vão de encontro ao papel ideal destinado a elas: casamento, maternidade e família. Se a história de Guta não se encerra com um happy end, mostrando a protagonista a lembrar da vida com as amigas no Colégio, é preciso pensar no descompasso entre a personalidade de Maria Augusta e a realidade que a cercava. ${ }^{30}$

Evidentemente, Conceição e Maria Augusta têm as suas aproximações e contrastes, reflexão a que não se propõe este trabalho. De qualquer forma, é preciso pensar que a própria Guta, conforme seu desenvolvimento intelectual e de leitora, posicionar-se-á de forma crítica diante das leituras da adolescência:

Nesta nova fase comecei a ler como adolescente, como a quase mulher em que me ia transformando depressa. A querer os livros onde falassem de amor, os eternos e róseos romancinhos franceses, em que homens cheios de espírito e de tédio, cansados das sereias e dos paradoxos, se apaixonam pelas ingênuas de dezesseis anos.

E a poesia, a grande e divina poesia!

Mas agora, digo como o velho Rousseau: é preciso não mentir. A poesia me envolveu, me sufocou, me raptou, é bem verdade. Mas na sua forma mais banal e subalterna - nos sonetinhos sentimentais, nas coisas leves e triviais do amor. (...)

A poesia, a grande poesia, verdadeira e poderosa, essa só me possuiu lentamente, quando minha alma foi perdendo aos poucos as sucessivas capas que a cobriam. Quantos anos levei, quantas almas gastei em emoções de

\footnotetext{
${ }^{29}$ QUEIROZ. As três Marias, p. 36.

${ }^{30}$ SILVA. A construção ficcional do feminino em Rachel de Queiroz.
} 
segunda ordem, até ser capaz de entender e sentir sozinha a beleza da Filha do rei $?^{31}$

Do depoimento de Maria Augusta, nota-se que, se por um lado a poesia poderosa, exemplificado no trecho por “A filha do rei”, de Manuel Bandeira - a quem, inclusive, o romance As três Marias é dedicado -, demorou a chegar, por outro, a poesia fácil foi responsável por prepará-la para, sozinha, ser capaz de se aventurar pela alta literatura. De acordo com Pennac, "não é porque essa mocinha coleciona Sabrina que ela vai acabar engolindo arsênico numa concha. Forçar a mão nesse estágio de suas leituras é nos separar dela, negando nossa própria adolescência.”32 Além disso, conforme já afirmou Calvino, “para poder ler os clássicos, temos de definir 'de onde’ eles estão sendo lidos, caso contrário tanto o livro quanto o leitor se perdem numa nuvem atemporal”. ${ }^{33}$ Pensando por esse lado, a leitura dos “romancinhos franceses” e dos versos sentimentais já não se afigura tão destrutiva para a personagem Guta. O senso crítico viria depois, acompanhado da ampliação do conhecimento da experiência humana.

Este trabalho procurou evidenciar a importância, no romance As três Marias, de Rachel de Queiroz, da ligação entre as referências literárias e a construção da subjetividade da personagem Guta. Outras discussões poderiam ser feitas sobre as alusões à leitura literária no romance, como o afastamento do personagem Luciano dos livros - “(ele detesta livros)”34 em virtude possivelmente da forma com que a escola os tratava: o ambiente escolar não era querido pelo personagem, que tinha medo da professora e horror de frequentá-lo.

Como o trabalho dedicou-se à personagem Guta e, mesmo assim, selecionando as passagens para análise - outras tantas poderiam ser evocadas -, objetivou-se ler a construção da subjetividade de Guta como um desenvolvimento da leitora. Se amadurecida Guta procurará uma literatura que dê conta de suas necessidades, também adolescente Maria Augusta procurará os livros que mais dizem respeito à sua sensibilidade. Vivendo em um internato e compartilhado os sonhos e anseios com as amigas, Guta conceder-se-á o direito ao bovarismo, defendido por Daniel Pennac em Como um romance. Atitude que, confiantes de nosso senso crítico e lucidez diante da realidade, sempre julgamos partir dos outros, como se

\footnotetext{
${ }^{31}$ QUEIROZ. As três Marias, p. 33-34.

${ }^{32}$ PENNAC. Como um romance, p. 158.

${ }^{33}$ CALVINO. Por que ler os clássicos, p. 14.

${ }^{34}$ QUEIROZ. As três Marias, p. 108.
} 
Madame Bovary fosse somente o outro. Como escreveu Pennac, entretanto, "Emma devia compartilhar essa convicção.”35

\begin{abstract}
This work contemplates the composition of the narrator Maria Augusta, Guta from Rachel de Queiroz's novel As três Marias [The three Marias]. To discuss the construction of her subjectivity, we look for literary allusions in the book, enabling the analysis of the protagonist as a reader, as well as her romanticized view of reality.
\end{abstract}

\title{
KEYWORDS
}

As três Marias [The three Marias], Rachel de Queiroz, subjectivity, literary allusions

\section{REFERÊNCIAS}

BAMBERGER, Richard. Como incentivar o hábito da leitura. Trad. Octavio Mendes Cajado. São Paulo: Cultrix/Brasília: INL, 1977. 118 p.

CALVINO, Italo. Por que ler os clássicos. Trad. de Nilson Moulin. São Paulo: Companhia das Letras, 1993. 280 p.

COUTINHO, Afrânio (Dir.). A literatura no Brasil. 7. ed. rev. e atual. São Paulo: Global, 2004. v. 5. 660 p.

FHILADELFIO, Joana Alves. Literatura, indústria cultural e formação humana. Cadernos de Pesquisa, n. 120, p. 203-219, nov. 2003. Disponível em: <http://www.scielo.br/pdf/cp/n120/a11n120.pdf>. Acesso em: 10 mar. 2011.

NERY, Hermes Rodrigues. Presença de Rachel: conversas informais com a escritora Rachel de Queiroz. Ribeirão Preto, SP: FUNPEC-Editora, 2002. 262 p.

PENNAC, Daniel. Como um romance. 3. ed. Trad. Leny Werneck. Rio de Janeiro: Rocco, 1993. $168 \mathrm{p}$.

PINTO, Cristina. O Bildungsroman feminino: quatro exemplos brasileiros. São Paulo: Perspectiva, $1990.160 \mathrm{p}$.

QUEIROZ, Rachel de. As três Marias. 24. ed. Rio de Janeiro: José Olympio, 2005. 208 p.

SILVA, Wanessa Regina Paiva da. A construção ficcional do feminino em Rachel de Queiroz. In: COLÓQUIO INTERNACIONAL DE ESTUDOS LINGUÍSTICOS E LITERÁRIOS, 1.; COLÓQUIO DE ESTUDOS LINGUÍSTICOS E LITERÁRIOS, 4., 2010, Maringá. Anais... Maringá: Universidade Estadual de Maringá, 2010, p. 1-10. Disponível em: <http://www.cielli.com.br/downloads/361.pdf>. Acesso em: 10 mar. 2011.

\footnotetext{
${ }^{35}$ PENNAC. Como um romance, p. 158.
} 
SODRÉ, Muniz. Teoria da literatura de massa. Rio de Janeiro: Tempo Brasileiro, 1978. 130 p. (Biblioteca Tempo Universitário, v. 49) 